\title{
Mapeamento da Vegetação e Fitogeografia do Município de Garanhuns-PE
}

\author{
Mapping of Vegetation and Phytogeografy of the City of Garanhuns-PE \\ Samuel Othon de Souza Costa', Elaynne Mirele Sabino de França², Carlos Eduardo Santos de Lima ${ }^{3}$, \\ Djenane Regina Maia de Lima ${ }^{4}$, Daniel Dantas Moreira Gomes ${ }^{5}$ \\ 1,3 Estudante de Licenciatura Geografia, Universidade de Pernambuco, Campus Garanhuns, Pernambuco, Brasil \\ ${ }^{2}$ Graduada de Licenciatura Geografia, Universidade de Pernambuco, Campus Garanhuns, Pernambuco, Brasil \\ ${ }^{4}$ Geógrafa e Especialista em gestão ambiental, Brasil \\ ${ }^{5}$ Doutorando em Geologia pela UFC, Universidade de Pernambuco, Campus Garanhuns. Pernambuco, Brasil
}

\begin{abstract}
Resumo
O presente trabalho tem como objetivo desenvolver o mapeamento da vegetação e da fitogeografia, de modo a apresentar as informações cartográficas produzidas para apoio de planejamentos do município de Garanhuns, no agreste meridional do estado de Pernambuco, a uma distância de $228 \mathrm{~km}$ da capital, Recife. As geotecnologias têm a objetividade como um dos seus princípios, obtendo dados e imagens que podem ser usados no mapeamento vegetal, uma vez que há uma série de informações para serem tratadas, analisadas e integradas. Foram utilizadas imagens de satélite disponibilizadas pelo INPE, que foram tratadas com o software ARCGIS 10.2 para aperfeiçoar a visualização e a representação das imagens. A produção de uma base de dados cartográficos do município de Garanhuns, com auxílio das informações fornecidas pelo IBGE e pela EMPRAPA, permite-nos uma maior compreensão da área vegetal, considerando os processos de bióticos e abióticos, e compreendendo, assim, os resultados significantes para o mapeamento dos aspectos físicos de todo o município e o melhoramento do Plano Diretor da cidade.
\end{abstract}

Palavras-chave: Mapeamento, Vegetação, Fitogeografia.

\begin{abstract}
This work aims at mapping the vegetation and phytogeography, like trying to present cartographic information produced to support the planning of the municipality of Garanhuns in rugged southern state of Pernambuco, a distance of $228 \mathrm{~km}$ from the capital, Recife. Geotechnologies has as one of its principles, speed and objectivity in obtaining data and images and can be used in plant mapping, given a set of information to be processed, analyzed and integrated. Satellite images, available at INPE, which were treated with the software ARCGIS 10.2 , aiming to improve the visualization and representation of the images were used. The production of a cartographic database of the municipality of Garanhuns, aided by information provided by IBGE and EMBRAPA, allow us a better understanding of plant area, considering the biotic and abiotic processes, comprising thus significant for mapping results throughout the municipality and improvement of the Master Plan of the city.
\end{abstract}

Keywords: Mappeing, Vegetation, Phytogeography. 


\section{INTRODUÇÃO}

A fragilidade dos ambientes naturais diante das intervenções humanas é maior ou menor em função de suas características genéticas. Em princípio, salvo algumas regiões do planeta, os ambientes naturais mostravam-se em estado de equilíbrio dinâmico até o momento em que as sociedades humanas passaram a intervir cada vez mais intensamente na exploração dos recursos naturais para gerar riquezas, conforto, prazer e lazer (ROSS, 2009).

A degradação de ambientes naturais é perceptiva por uma série de fatores, como as degradações nos solos, a topografia, o clima, entre outros. No entanto, um fator é preponderante nas mudanças ambientais: a vegetação, que se torna fundamental para entendermos a morfodinâmica de um ambiente. Segundo Tricart (1977):

"A morfodinâmica depende da interação entre o clima, a topografia, o solo, material rochoso e a cobertura vegetal. Dentre estes fatores, a vegetação possui um papel de extrema importância; o de impedir a ação dos fenômenos erosivos, sobretudo em regiões onde a mesma se apresenta bem conservada". (p. 36, 1977)

A partir disso, sabemos que a vegetação tem um papel bastante interessante no que diz respeito aos processos morfodinâmicos, em outras palavras, nos fatores transformadores do ambiente. Em suma, segundo Bertrand (2004), a vegetação se comporta sempre como verdadeira síntese do meio.

Todas as atividades produtivas geradas pelo homem se iniciam através de um ataque direto à vegetação, mas a vegetação também possui características próprias que devem ser observadas e identificadas a partir do diagnóstico dos problemas da fragilidade, da avaliação, da potencialidade de regeneração e do seu uso, como se refere (PASSOS, 1998).

A vegetação como medidor de dinâmica ambiental nos leva a pensar que não apenas processos naturais causam tais mutações no meio, mas também intervenções antrópicas, que visam à melhoria da vida social humana muitas vezes sem considerar a importância da visão sustentável naquela área.

O objetivo geral desse entendimento integrativo - sociedade e natureza - consiste em obter um conjunto de informações elaborado e organizado que se consubstancie em um conteúdo básico. Assim, será possível desenvolver um planejamento de gestão para determinado espaço territorial diretamente atingido, com a finalidade de conservar, preservar e recuperar a natureza, e, ao mesmo tempo, promover o desenvolvimento econômico e social em bases sustentáveis (ROSS, 2009).

Tais mudanças ambientais podem interferir no desenvolvimento natural do ambiente, podendo trazer efeitos não desejados à sociedade. Contudo, os processos de interação entre homem e meio ambiente devem ser planejados; conforme afirma Drew (1986):

"Embora as atividades destinadas a alterar o ambiente, na sua maioria, tenham a intenção de ser benéficas do ponto de vista humano, o grau de inter-relação dos fenômenos naturais a que nos referimos explica que mudanças inesperadas, ou até reações em cadeia, venham a resultar daquilo que pretendia ser uma "benfeitoria" isolada". (DREW p.60, 1986)

Sob uma perspectiva de planejamento econômico e ambiental do território, seja municipal, estadual, federal, ou qualquer outra unidade, é absolutamente necessário que as intervenções humanas sejam planejadas com objetivos claros de ordenamento territorial, tomando como premissas a potencialidades dos recursos naturais e humanos, e as fragilidades dos ambientes naturais. É preciso por em prática as políticas públicas que visem o ordenamento territorial e que valorize a conservação e a preservação da natureza (ROSS, 2009).

Para tais planejamentos sobre o meio ambiente, sobretudo a vegetação, é preciso que se estude o assunto. Como a classificação é o principal componente de pesquisa, surge a fitogeografia, que leva em questão as características climáticas e pedológicas. Segundo Bertrand (2004), as classificações climáticas e pedológicas são tão gerais quanto teóricas.

Para planejar e caracterizar a vegetação, utilizam-se técnicas mais modernas, como as geotecnologias. Mais precisamente o geoprocessamento, que auxilia a representação cartográfica de mapas e pode ser bastante útil na confecção de mapas temáticos de vegetação e fitogeografia. Assim, estrutura e sistematiza em um Sistema de Informação Geográfica (SIG) para que, dessa forma, obtenha-se o 
planejamento do meio ambiente dinâmico; como afirma Fitz:

"Outra aplicação bastante prática dos SIGs, mais especificamente vinculada ao geoprocessamento, diz respeito à realização de análises de cunho espacial por meio de mapas temáticos diversos." (FITZ, p. 26, 2008)

Isso permite que se utilizem essas ferramentas para análises e monitoramentos de fenômenos naturais e antrópicos dinâmicos com uma maior facilidade e agilidade, servindo de apoio para que os governantes tenham acesso a mais informações.

Segundo Albuquerque et al. (2012), para que estudantes e gestores possam ter conhecimento e decisões seguras a partir de uma geoinformação, é necessário que se tenha qualidade e facilidade de acesso, além da confiabilidade dos dados georreferenciados.

Dessa forma, a utilização dessas tecnologias auxilia com dados advindos de imagens de satélite, que caracterizam o espaço e fornecem informações sobre os fenômenos presentes.

"As imagens de satélite, ao recobrirem sucessivas vezes a superfície terrestre, possibilitam o estudo e o monitoramento de fenômenos naturais dinâmicos do meio ambiente, como os da atmosfera, do vulcanismo, de erosão do solo, de inundação etc., e aqueles antrópicos, como o desmatamento". (FLORENZANO, p.81, 2011).

Observa-se que há grandes potenciais morfodinâmicos que podem trazer mudanças também na vegetação. Para tanto, foi feito um mapeamento da vegetação e fitogeográfico com o objetivo de aumentar o número de dados relativos à dinâmica ambiental que o meio está sujeito.

Foi possível obter informações do município de Garanhuns, que tem fatores antrópicos e naturais dinâmicos muito intensos, pois o município é o maior centro urbano de sua região e também tem alto nível de produtos advindos da zona rural.

Então foi realizado um mapeamento da vegetação para obter noções e representações dos tipos de vegetação onde o município está inserido, apresentando dados para interações estáveis entre o homem e o meio ambiente.

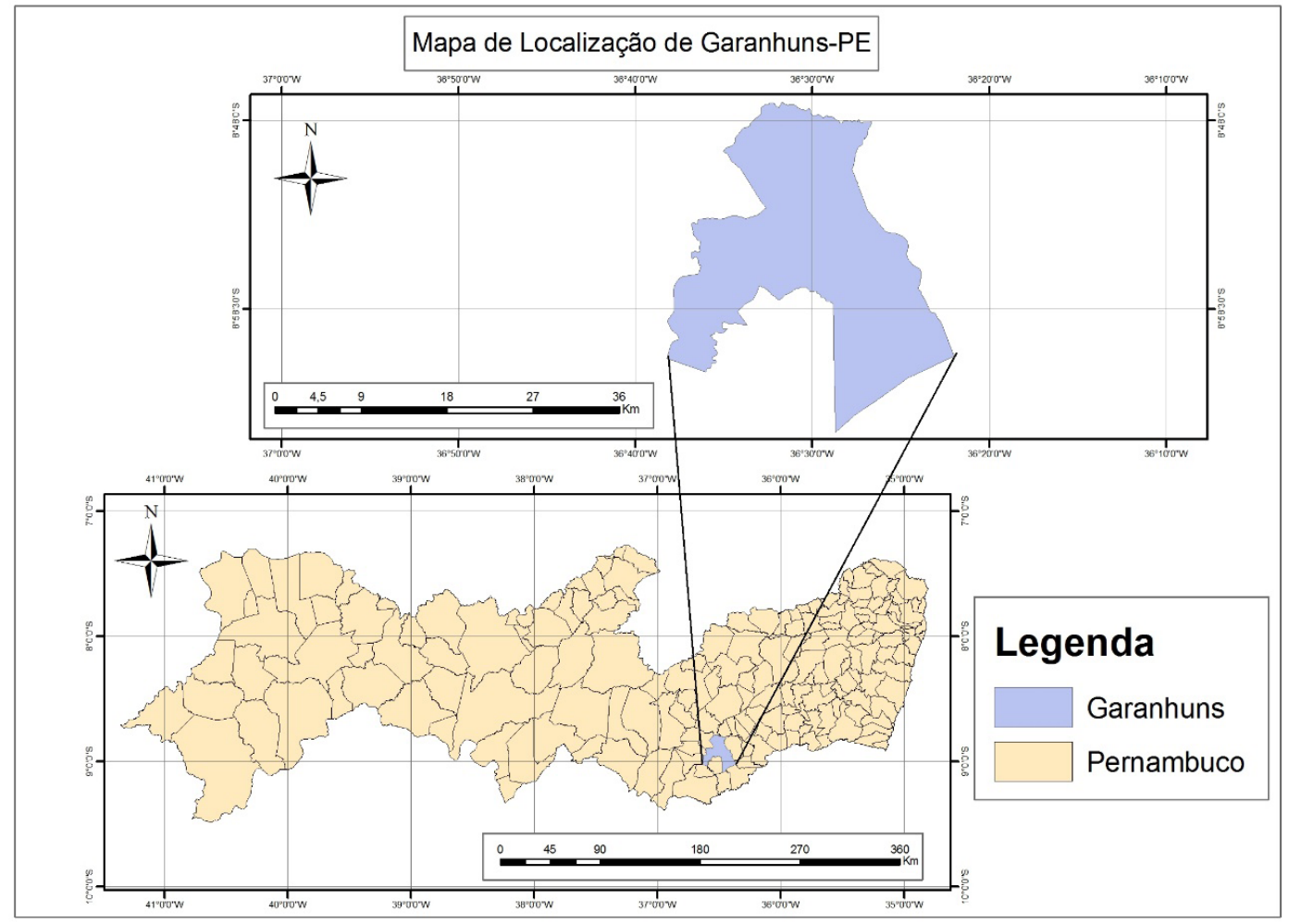

Figura 1: Mapa de Localização do município de Garanhuns-PE.

Fonte: Desenvolvidos pelos autores. 
Assim, junto com elementos da região, busca-se integrar as informações e construir um banco de dados que auxilie o mapeamento da vegetação e fitogeográfico do município de Garanhuns. São fornecidos meios de apoio ao planejamento dos gestores que, através do plano diretor participativo, podem fazer um gerenciamento mais eficiente, tratando da vegetação onde o município estudado se insere.

O levantamento fitogeográfico contribui de forma decisiva no planejamento por se destacar na variedade e na quantidade de informações que pode fornecer através da pesquisa in loco, promovendo a redução dos impactos ambientais negativos. (TROPPMAIR, 2002)

O município de Garanhuns/PE, está localizado no agreste meridional de Pernambuco a uma distância de $228 \mathrm{~km}$ de sua capital, Recife, estando delimitado: pelos paralelos $8^{\circ} 48^{\prime} 0^{\prime \prime} / 8^{\circ} 58^{\prime} 0^{\prime \prime} \mathrm{S}$ e pelos meridianos $36^{\circ} 10^{\prime} 0^{\prime \prime} / 36^{\circ} 50^{\prime} 0^{\prime \prime} \mathrm{W}$ (Figura 1).

\section{MATERIAIS E MÉTODOS}

Inicialmente foi realizado um levantamento bibliográfico com o objetivo de abranger informações relativas ao objeto de estudo desenvolvido, entre as quais foi obtido o Plano Diretor de Garanhuns.

Realizou-se uma pesquisa virtual que tinha como objetivo a inserção de informações do Manual Técnico da Vegetação Brasileira, do Instituto Brasileiro de Geografia e Estatística (IBGE), para a coleta de dados do agreste meridional de Pernambuco, zona onde o município de Garanhuns está inserido.

Posteriormente foram obtidos downloads de imagens de satélite pelo INPE (Instituto Nacional de Pesquisas Espaciais), que foram pré-processadas e georreferênciadas no SIG: ARCGIS 10.2. Realizaram-se, também, vetorizações para representar a vegetação e a fitogeografia do município.

Após essas etapas iniciais, foi realizado o processamento dos dados no ambiente do sistema de informações geográficas (SIG). Os vetores anteriormente tratados foram vinculados a um banco de dados e editados para o agrupamento de informações analógicas.

Dessa forma, foram confeccionados: um mapa de Localização Geográfica, um mapa fitogeográfico, um mapa sub-fitogeografico e um mapa de vegetação. Após as conclusões dos mapas, eles foram salvos em formato de extensão JPEG (Joint Photographic Experts Group).

\section{RESULTADOS E DISCUSSÕES}

A partir das pesquisas realizadas e da integração de informações relativas à vegetação e à fitogeografia foi realizado o mapeamento, dando condições para o planejamento da área de acordo com o tipo de vegetação e fitogeografia encontrada no município.

Para tanto, existe a necessidade de procurar novas opções para pesquisas de representação, coleta e tratamento de dados. As áreas tecnológicas proporcionam um amparo mais prático e rápido, como o geoprocessamento, para a aquisição e tratamento dos dados, com base no sensoriamento remoto e SIGs.

Nesse crescimento evolutivo de caracterizações através de mapas temáticos, os artifícios de interpretação foram aperfeiçoados e modernizados juntamente com as ampliações tecnológicas e científicas que nos permitem o mapeamento digital da vegetação. Isso porque se acredita que tanto esse processo quanto a vegetação representa um caráter dinâmico.

Além do caráter tecnológico, o fator político entra em cena no que diz respeito ao gerenciamento de áreas. O município de Garanhuns dispõe do Plano Diretor Participativo, que é obrigatório a cidades com uma população maior que 20 mil habitantes. Conforme fatores políticos em relação ao meio na zona urbana e rural, o artigo $25^{\circ}$ do Plano Diretor Participativo do município de Garanhuns diz:

"Fica criado, no âmbito da Secretaria Municipal de Planejamento de Garanhuns, o Conselho Municipal de Política Urbana (COMPUR), o qual exercerá suas atribuições juntamente com o Conselho Municipal de Defesa do Meio Ambiente (CODEMA)". (GARANHUNS, 2008)

Com dados espaciais e leis sobre gerenciamento e planejamento do meio ambiente, foi realizado o mapeamento da vegetação e da fitogeografia do município de Garanhuns, onde foram pesquisadas através de pesquisas ao Manual de Técnico da Vegetação Brasileira do IBGE, entre outros.

Primeiramente, a vegetação de Garanhuns foi mapeada, identificando dois tipos: floresta estacional semidecidual e áreas de tensão ecológica (Figura 2), que são características da região em que 
o município está inserido.

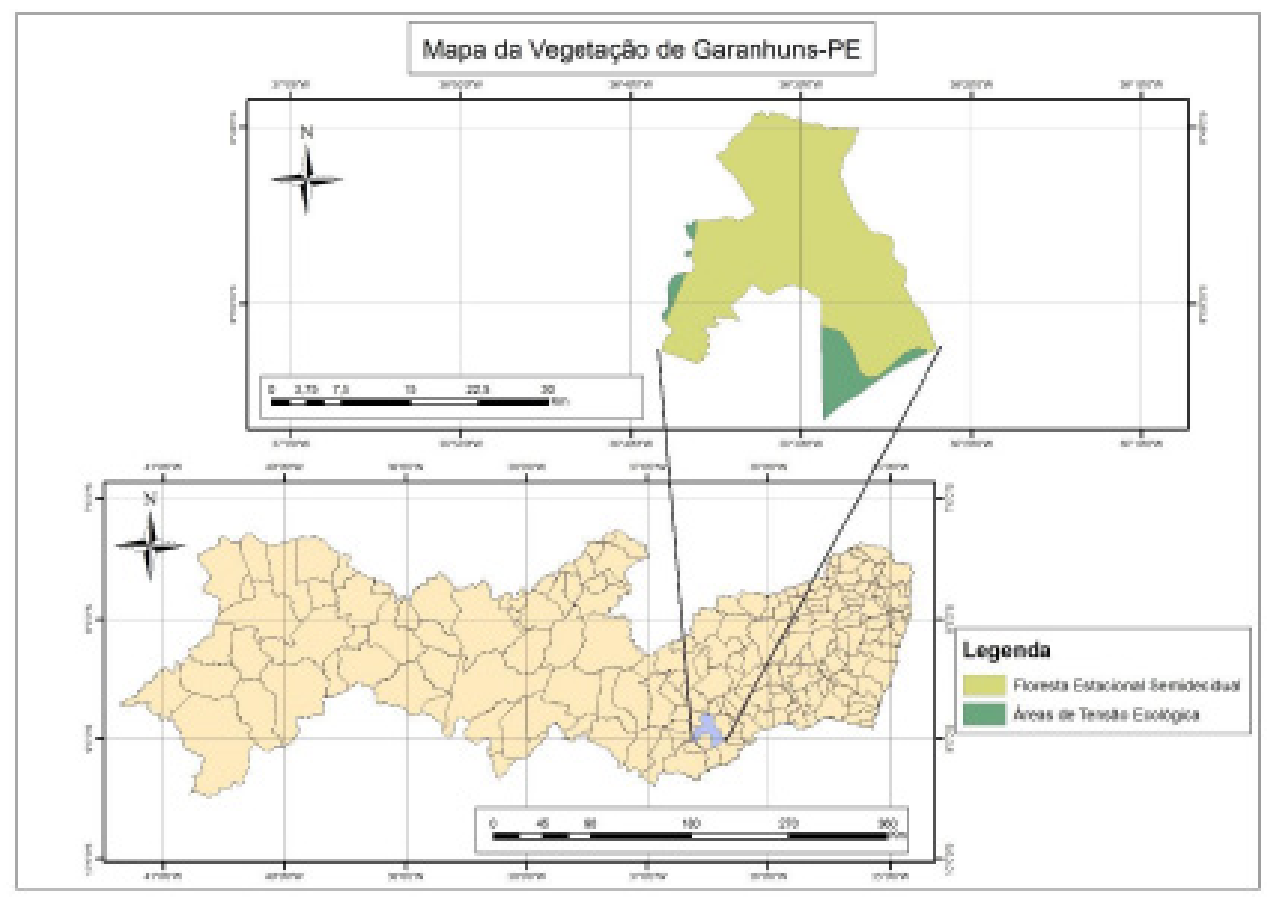

Figura 2: Vegetação do Município de Garanhuns-PE

Fonte: Desenvolvidos pelos autores.

As características da floresta estacional semidecidual que, segundo a Agência Embrapa de Informação Tecnologia - AGEITEC, estão atreladas às influências climáticas e à sua vegetação, pode regular o balanceamento hídrico e perder as folhas em menor incidência de chuva ou aumentar a quantidade de folhas numa maior quantidade de precipitação. A floresta estacional semidecidual pode ter árvores com altura de aproximadamente $40 \mathrm{~m}$, seu extrato arbustivo é rico em biodiversidade de plantas, e as herbáceas são compostas por uma gama de tipos de vegetação.

As características das áreas de tensão ecológica, de acordo com a Agência Embrapa de Informação Tecnologia (AGEITEC), são espaços geográficos localizados na interface entre múltiplos ecossistemas, sujeitos ou não aos processos antrópicos. Estão sujeitos a transições de vegetação, dando uma mistura florística na região.

Em seguida do mapeamento da vegetação, foi realizado o mapeamento da fitogeografia e da sub-fitogeografia do município de Garanhuns, contextualizando geograficamente a região.

Assim, o mapeamento da fitogeografia do município constatou a presença de dois tipos, a caatinga e a mata (figura 3), onde se faz presente o processo de transição fitogeográfico de Pernambuco.

Segundo a Agência Embrapa de Informação Tecnologia - AGEITEC, a caatinga é caracterizada por apresentar clima semiárido, com ocorrência de secas estacionais e periódicas, o que estabelece regimes intermitentes aos rios e deixa a vegetação sem folhas no período seco. Nos períodos de chuva, a folhagem das plantas volta a brotar e a ficar verde.

As características da Mata originalmente vêm da mata atlântica que, conforme a Agência Embrapa de Informação Tecnologia - AGEITEC, apresenta clima tropical com influência do Oceano Atlântico, e floresta tropical úmida que é formada por florestas ombrófilas densa, aberta e mista e por florestas estacionais semi-deciduais e deciduais.

Para dar mais clareza às informações aqui fornecidas, a realização da confecção do mapeamento da sub-fitogeografia, deu-se a partir da utilização da escala mais especifica da área desses biomas como meio esclarecedor.Dessa forma, foi feito o mapeamento sub-fitogeografico e constatou-se a presença de dois tipos: o agreste e a mata úmida (figura 4), que são bastante perceptíveis na região.

De acordo com as especificidades apresentadas no Manual Técnico da Vegetação Brasileira, segundo o IBGE, a mata úmida se caracteriza por apresentar gêneros amazônicos endêmicos de famílias Pantropicais como, por exemplo, as Fabaceae Mim., Parkia pendula (Willd.) Vent. ex Walp. (visgueiro) 
e Enterolobium maximum Ducke (fava), a Fabaceae Caes. Hymenaea latifolia Hayne (jatobá) e as Fabaceae Caes. Peltogyne pauciflora Vent. (roxinho), Diplotropis purpurea (Rich.) Amshoff (sucupira), a Fabaceae Pap. Myroxylon cf. balsamum (L.) Harms (bálsamo) e muitas outras, que, segundo Andrade-Lima (1966a), chegam a 19 gêneros e 388 espécies comuns às duas regiões, Nordeste e Amazônica.

Segundo dados levantados no Manual Técnico da Vegetação Brasileira, o agreste tem características situadas entre as áreas costeiro-úmida e interiorano-árida, apresentando ochlospecies bem características como, por exemplo, Zizyphus joazeiro (juazeiro, Rhamnaceae), que ocorre também ao longo dos cursos de água intermitentes.

Por meio destas informações, já se sabe que tipos de vegetação fitogeografias e sub-fitogeografias serão encontradas nos domínios territoriais do município de Garanhuns.

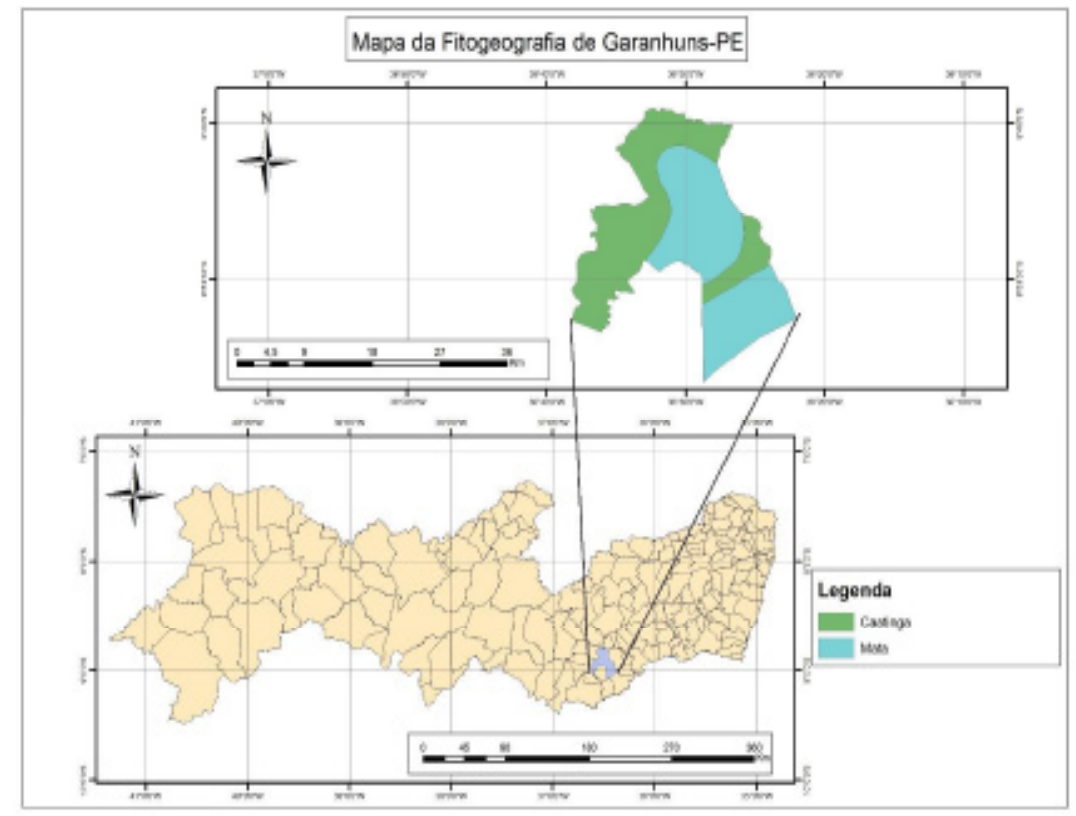

Figura 3: Fitogeografia do Município de Garanhuns-PE.

Fonte: Desenvolvidos pelos autores.

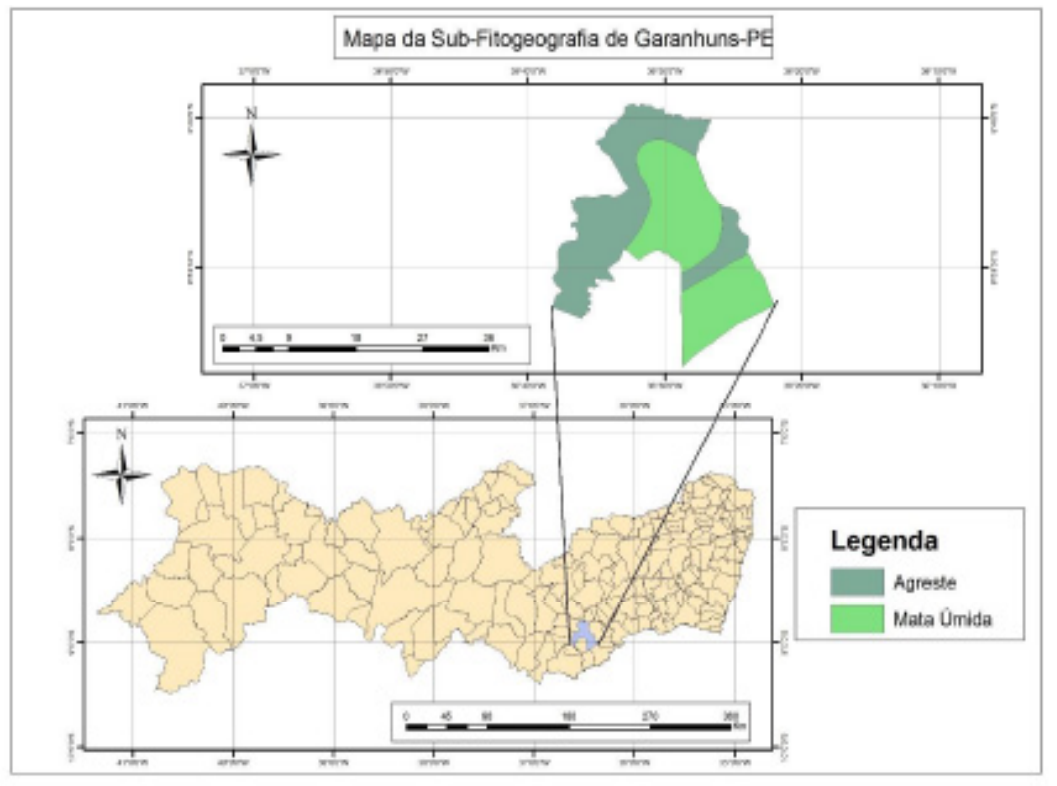

Figura 4: Sub-fitogeografia do Município de Garanhuns-PE.

Fonte: Desenvolvido pelos autores. 


\section{CONCLUSÃO}

Os fatos sobre a vegetação e suas classificações fitogeográficas estão atrelados à dinâmica do meio ambiente, além de ser um fator determinante ao planejamento de áreas urbanas ou rurais. Portanto, fica clara a importância de se pesquisar as interações entre o homem e o meio.

As pesquisas sobre vegetação têm cunho sistêmico, pois integra fatores ambientais como pedologia, geologia, climática, entre outros. No entanto, sua essencialidade é fundamental para a caracterização de áreas do meio ambiente e a indicação de degradação.

Com a necessidade de entender a vegetação, o mapeamento vem como técnica de auxílio na investigação do meio. A facilidade no manuseio e a agilidade da ferramenta, o geoprocessamento proporciona resultados concretos como base ao planejamento prático às áreas estudadas.

O município de Garanhuns se localiza numa área de transição entre a mata e o sertão, que é denominada de agreste. Sua vegetação tem aspectos de uma mistura dos materiais vegetais.

Dessa forma, conclui-se os tipos de vegetação, de fitogeografia e de sub-fitogeografia através de técnicas de geoprocessamento e com a integração de informações que ajudam a fomentar as concepções do meio ambiente em uma região, dando condições de serem mapeadas.

\section{REFERÊNCIAS}

ALBUQUERQUE, E. L. S; "B." SIG-WEB Ceará em mapas interativos. In: MEDEIROS, C. N.; GOMES, D. D. M.; CRUZ, M. L. Novas ferramentas na cartografia escolar. Mercator, Fortaleza, v. 11, n. 24, p. 253-269, jan./abr. 2012.

BERTRAND, G. Paisagem e Geografia Física Global. Esboço Metodológico. Curitiba, Editora UFPR, 2004.

DREW, D. Processos Interativos Homem-Meio Ambiente. São Paulo, Difel, 3º Ed, 1986.

FLORENZANO, T, G. Iniciação em Sensoriamento Remoto. São Paulo, $3^{\circ}$ Ed, Oficina de Textos, 2011.

FITZ, P. R. Geoprocessamento sem Complicação. São Paulo, Oficina de Textos, 2008.

GLOSSARIO AMBIENTAL-AGENCIA EMPRABA DE INFORMAÇÃO TECNOLOGICA. Disponível em <http://www.agencia.cnptia.embrapa.br/gestor/especies_arboreas_brasileiras/arvore/CONT000g08hphpk02wx5ok026zxpg7c9wrkm.html>

GARANHUNS. Decreto-lei no 3620, de 23 de dezembro de 2008. Institui o Plano Diretor Participativo do Município de Garanhuns, instrumento da política urbana e ambiental, e dá outras providências. Garanhuns, 2008.

MANUAL TECNICO DA VEGETAÇÃO BRASILEIRA, IBGE, Rio de Janeiro, $2^{\circ}$ Ed, 2012.

PASSOS, M.M. 1998. Biogeografia e Paisagem. Maringá, Paraná, UEM. Presidente Prudente. São Paulo. UNESP.

ROSS, Jurandyr. Ecogeografia do Brasil: subsídio para planejamento ambiental. São Paulo: Oficina de Textos, 2009.

TROPPMAIR, H. Biogeografia e Meio Ambiente. Rio Claro, São Paulo. 5ª Ed, 2002.

TRICART, J. Ecodinâmica. Rio de Janeiro, IBGE, Diretoria Técnica, SUPREN, 1977. 